\title{
Desinstitucionalización del sistema de partidos en Colombia: reformas políticas y consecuencias sobre los pequeños partidos de izquierda
}

\section{Deinstitutionalization of the party system in Colombia: political reforms and consequences on small left parties}

\author{
Mary Luz Sandoval Robayo*
}

\begin{abstract}
Resumen: La primera parte de este artículo está constituida por el marco teórico donde se toma como referencia la hipótesis de Levitsky, Loxton y Dyck (2016) según la cual existe un impacto limitado del diseño institucional sobre la construcción de partidos en América Latina, hipótesis que se busca contrastar para el caso colombiano. Para ello se analizan las causas y consecuencias de la desinstitucionalización del sistema de partidos, las reformas políticas de 2003 y posteriores y la manera como éstas incidieron en particular sobre los partidos de izquierda más pequeños.
\end{abstract}

Palabras claves: Reformas políticas, estrategias, partidos políticos, izquierda.

\begin{abstract}
The first part of this article is constituted by the theoretical framework where it is taken as a reference the hypothesis of Levitsky, Loxton, Dyck and Domínguez (2016), according to which there is a limited impact of the institutional design on construction of parties in Latin America, this article seeks to contrast that hypothesis for the Colombian case. To this goal, the causes and consequences of the deinstitutionalization of the party system, the political reform of 2003 and subsequent, and the way in which they impacted particularly on the smaller left parties are analyzed.
\end{abstract}

Key words: Political reforms, strategies, political parties, left.

Recibido: 19 diciembre 2017

Aceptado: 28 enero 2018

\footnotetext{
* Nacionalidad Colombiana. Socióloga, Magister en Sociología de la Universidad Nacional de Colombia. Candidata a Doctora en Ciencias Políticas de la Universidad Torcuato Di Tella, Buenos Aires - Argentina. Profesora Asociada, Departamento de Antropología y Sociología de la Universidad de Caldas, Manizales Colombia. Email: maryluz.sandoval@ucaldas.edu.co
} 


\section{Introducción}

El marco teórico general está dado por la explicación que buscan Levitsky, Loxton y Van Dyck (2016) al hecho de que incluso luego de cuatro décadas de la entrada de la ola democratizadora a América Latina, los partidos políticos en esta región continúan siendo débiles, muchos de ellos se han desvanecido o colapsado en países como Argentina, Bolivia, Colombia, Costa Rica, Ecuador, Guatemala, Perú y Venezuela ${ }^{1}$. Entre los factores que inciden en la construcción exitosa de partidos, según estos autores está el papel jugado por el diseño institucional y las reglas en general, aunque establecen que éstas tienen un impacto limitado sobre los procesos de construcción de partidos. En el marco teórico se selecciona solo este factor a pesar de que los autores señalen varios otros, con el fin de contrastar esta hipótesis empíricamente en particular respecto de su incidencia sobre los partidos políticos pequeños de izquierda en Colombia. Con ello se busca comprobar que contrario a la hipótesis de Levitsky, Loxton y Van Dyck para otros casos, las reformas políticas si tuvieron un impacto importante sobre la construcción de partidos en Colombia.

Existen dos tipos de hipótesis que explican las estrategias de los partidos de la nueva izquierda democrática en Colombia: estructurales y agenciales. Las primeras establecen que las instituciones se comportan de manera inercial y para las segundas, las instituciones son factores que pueden ser alterados por los actores ${ }^{2}$. Las reformas políticas funcionan como una hipótesis estructural, dada por las circunstancias que constituyeron inicialmente el contexto de la unidad de la izquierda. Las reformas políticas de 1991 y 2003 fueron consecuencia del proceso de desinstitucionalización de los partidos tradicionales Liberal y Conservador que inició con el Frente Nacional ${ }^{3}$. Las posteriores reformas (2005, 2009 y 2011) han incidido de manera diferenciada sobre la izquierda.

El impacto de la reforma política de 2003 estuvo mediado por la dinámica del conflicto armado interno y la influencia de las élites locales. Esta reforma no mejoró las garantías electorales. En ese año en el $15 \%$ de los municipios del país no fue posible ejercer el derecho a elegir y ser elegido, hubo candidaturas únicas para alcaldías, amenazas a candidatos y partidos políticos y no se pudieron celebrar elecciones en once [11] municipios donde no se inscribieron candidatos debido al orden público ${ }^{4}$. El Acto Legislativo 02 de 2004 que permitió mediante métodos fraudulentos la reelección de

\footnotetext{
${ }^{1}$ Steven Levitsky, James Loxton, Brandon Van Dyck y Jorge I. Domínguez, Challenges of Party-Building in Latin America, Cambridge, Cambridge University Press, 2016, 1.

${ }^{2}$ Kathleen Thelen, “Historical Institutionalism in Comparative Politics”. Annu. Rev. Polit. Sci. (2), $1999,369$.

${ }^{3}$ Margarita Batlle y José Ricardo Puyana, "Reformas políticas y partidos en Colombia: cuando el cambio es la regla", Politai, Revista de Ciencia Política, Año 4, Segundo Semestre, No 7, 2013, 75.

${ }^{4}$ Gary Hoskin y Miguel García Sánchez, La reforma política de 2003 ¿La salvación de los partidos políticos colombianos? Bogotá, Universidad de Los Andes, Departamento de Ciencia Política, Fundación Konrad Adenauer, London School of Economics and Political Science, 2006, 103.
} 
Álvaro Uribe, fue en cambio un factor en contra de la izquierda por cuanto favorecía claramente a un candidato sobre los demás 5 .

Ninguna de estas reformas detuvo la amenaza a la institucionalidad provocada por los grupos paramilitares, fenómeno que se expandió con mayor fuerza en parte como resultado justamente del debilitamiento de los partidos políticos. Las reformas crearon incentivos para pactar las reglas electorales y las estrategias de coalición electoral de los partidos de derecha y de las distintas corrientes de la izquierda. Estas reformas electorales que inicialmente establecieron un umbral electoral de 2\% (2003) y luego lo elevaron al 3\% (2009) influyeron negativamente sobre los partidos de izquierda pequeños como las disidencias de Progresistas y Partido de los Trabajadores de Colombia, PTC del Polo Democrático Alternativo, PDA. Gustavo Petro de Progresistas (actual candidato a la presidencia) y Marcelo Torres del PTC (actualmente en la cárcel), criticaron las consecuencias prácticas antidemocráticas de estas reformas ${ }^{6}$.

Otros factores estructurales por constituir tendencias históricas y culturales del país son: la tendencia nacional hacia la abstención ${ }^{7}$, la tendencia ideológica hacia la derecha ${ }^{8}$ y la desconfianza frente a los partidos políticos, los cuales no serán abordados aquí ${ }^{9}$.

El presente artículo se divide en cinco partes, la primera está constituida por un breve marco teórico donde se reseña la hipótesis que se busca contrastar, la segunda establece las causas y consecuencias de la desinstitucionalización del sistema de partidos, la tercera reseña los factores de cada una de las reformas políticas que incidieron sobre los partidos y en particular, sobre los partidos de izquierda; la cuarta parte enfatiza las consecuencias de estas reformas sobre los partidos de izquierda más pequeños en Colombia y por último se

\footnotetext{
${ }^{5}$ Periódico eltiempo.com 15/04/2015, "Yidispolítica, el escándalo que nos dejo la reelección de Uribe. La Corte condenó este miércoles a Sabas Pretelt y Diego Palacio por entregar dádivas" en <http://www.eltiempo.com/politica/justicia/que-es-la-yidispolitica/15575795> Consultado 01/02/2016.

6 "Lo que hemos presenciado desde hace varios años es que ese tipo de normatividad ha producido una dispersión de las fuerzas progresistas y democráticas (....) el afán a último momento de ver [sic] en dónde me meto para poder ser un candidato, ha hecho que sectores del progresismo y de la democracia colombiana estén en el Partido Liberal unos y otros en la ASI y otros en el Partido Verde y otros en el Polo y otros buscan firmas como nosotros y otros en el MAIS, etc., y si viene otra elección bajo esas mismas condiciones, aumentará la dispersión y es una cosa que en el caso de Bogotá con Clara López al final fue determinante, porque no estábamos unidos, ahí cada fuerza fue reaccionando primero fue probando etc., y fue perdiendo unos tiempos vitales mientras que la candidatura de Peñalosa iba aglutinando la derecha, al uribismo y al vargasllerismo, juntos hicieron la mayoría que hoy gobierna (Discurso de Gustavo Petro de 22 de enero de 2016).

${ }^{7}$ Registraduría del Estado Civil en

<http://elecciones.registraduria.gov.co:81/esc_elec_2015/99AL/DAL16ZZZZZZZZZZZZZZZ_L1.htm> consultado 20/01/2017.

8 Juan Carlos Rodríguez-Raga, "Izquierdas y derechas en Colombia. Una mirada rápida a los rasgos sociodemográficos del espectro ideológico del país", revista Colombia Internacional, No 66, julio-diciembre de 2007, 184-193.

9 Departamento Nacional de Estadística, DANE, Encuesta Cultura Política 2015 en <https://formularios.dane.gov.co/Anda_4_1/index.php/catalog/406> consultado 10/04/2017.
} 
plantean algunas conclusiones donde se advierte la imposibilidad de generalizar la hipótesis de Levitsky, Loxton y Van Dyck para el caso colombiano y algunos posibles debates para un futuro de corto plazo.

\section{Marco teórico}

Se ha generado un consenso casi total y muy amplio en la ciencia política acerca de la idea según la cual la democracia es impensable sin la presencia de los partidos políticos, no obstante, aún después de varias décadas de democracia en la región latinoamericana, los partidos siguen siendo estructuras débiles. A partir de la década del 90 especialmente esta ha sido una tendencia hasta el punto de hablarse de colapso de muchos partidos políticos en la región ${ }^{10}$. Levitsky, Loxton y Van Dyck buscan explicar la variación en los resultados de la construcción de partidos en América Latina desde la tercera ola democratizadora hasta el presente y por qué algunos de estos nuevos partidos han perdurado y otros han fallado. En aquellos países donde los partidos son débiles o donde los sistemas de partidos se descomponen y no son reconstruidos, las democracias sufren problemas de gobernabilidad crisis constitucionales e incluso colapsan, en cambio donde permanecen fuertes y los sistemas de partidos se institucionalizan, las democracias permanecen estables ${ }^{11}$. Los autores argumentan principalmente que los partidos más robustos no emergen en contextos de estabilidad sino, por el contrario, aparecen en el marco de conflictos extraordinarios, en periodos de una gran polarización, acompañados por movilizaciones populares a gran escala, violencia o represión. Esto hace que se generen lazos partidarios más estrechos, organizaciones con raigambre social y suficiente cohesión interna como para que puedan construirse de forma exitosa.

La propuesta teórica en la cual se enmarca el presente análisis se ha focalizado en una hipótesis alterna desarrollada en este texto según la cual el diseño institucional entendido como las reglas constitucionales y electorales que dan forma y son un incentivo de coordinación y agregación a los partidos nacionales para políticos y votantes, tienen en realidad un impacto limitado sobre la construcción de los partidos. Algunos académicos han estudiado el impacto electoral y otros obstáculos institucionales sobre la formación de partidos en América Latina, por ejemplo, han establecido que los sistemas de la lista abierta y la representación proporcional electoral debilitan a los partidos y en cambio fortalecen las estrategias centradas en los candidatos, esas explicaciones según Levitsky, Loxton y Van Dyck, no dan cuenta de la capacidad de enraizamiento de los partidos. Las reglas electorales desde el punto de vista de estos autores pueden modelar los incentivos para la formación de partidos, pero no generan ligazón partidaria ni redes activistas fundamentales para la sobrevivencia en el largo plazo de los partidos. En América Latina, estas reglas no impactan el proceso de construcción de partidos ${ }^{12}$. Incluso muchas veces los partidos nuevos se consolidan en contextos institucionales poco propicios. En consideración a la

\footnotetext{
${ }^{10}$ Steven Levitsky, James Loxton, Brandon Van Dyck y Jorge I. Domínguez, ibidem.

${ }^{11}$ Levitsky, Loxton y Van Dyck, Ibid, 2.

${ }^{12}$ Levitsky, Loxton y Van Dyck, Ibid, 9-10.
} 
concisión, se dejan de lado todos los demás factores desarrollados por los autores para explicar cuándo y por qué son exitosos los partidos políticos en términos de su perduración. En cambio, se desarrollan a continuación argumentos que buscan matizar esta hipótesis sobre la incidencia de las normas, a partir del caso de la izquierda colombiana.

\section{La desinstitucionalización del sistema de partidos}

En contraste con lo anterior, en Colombia existe una relación generalmente aceptada entre la desinstitucionalización del sistema de partidos y las reformas políticas ${ }^{13}$. Esta crisis está inserta en el continuo histórico entre el Frente Nacional (1957-1986), la Constitución de 1991, la reforma política de 2003 y las posteriores reformas políticas.

Los partidos políticos tradicionales Liberal y Conservador nacieron a mediados del siglo XIX y mantuvieron su predominio a través de la lucha violenta en diversas etapas de la vida republicana. Estas luchas se presentaron de forma intermitente durante la primera mitad del siglo XX y culminaron con la llamada época de "la violencia" iniciada antes del Bogotazo provocado por el asesinato del líder liberal Jorge Eliécer Gaitán el 9 de abril de 1948.

El cambio del bipartidismo al multipartidismo parecía poco probable en un país en el que los partidos tradicionales arraigaron desde mediados del siglo XIX. Sin embargo, la disolución de las diferencias entre los partidos tradicionales inicia durante el Frente Nacional (1957-1986), régimen de alternación del poder político que surge como necesidad de superación de la etapa de violencia, mediante el pacto entre los partidos Liberal y Conservador que llevó a una junta militar al poder (1957-1958). La culminación de la dilución de los clivajes ideológicos entre estos dos partidos, se da en medio de un contexto de disolución de los clivajes ideológicos a nivel internacional: el final de la Guerra Fría termina por horadar las viejas ideas de un Partido Conservador católico anquilosado en las antiguas creencias que le dieron origen en el siglo XIX, así como deslegitimó las ideas radicales de las guerrillas comunistas surgidas durante el Frente Nacional como respuesta al cierre del régimen a opciones políticas distintas de los partidos tradicionales.

Entre 1985 y 1991 Colombia estuvo atravesada por la violencia del paramilitarismo y de los carteles de la droga. La constituyente fue precedida por atentados que buscaron desestabilizar el Estado colombiano. Los carteles de la droga retaron al Estado y atacaron a las fuerzas políticas más democráticas y progresistas. A la vez la violencia paramilitar se ejerció contra los partidos de izquierda legal (Partido Comunista de Colombia) o que iniciaban procesos de incorporación a la vida civil (Unión Patriótica, M-19).

\footnotetext{
${ }^{13}$ Santiago José Castro Agudelo, Del dicho al hecho: reformas políticas y sistema de partidos en Colombia 2002-2010. Transformaciones en el sistema de partidos en Colombia a partir de las reformas políticas de 2003 y 2009 y la reelección presidencial, Bogotá, Institución Universitaria Politécnico Grancolombiano, 2012.
} 
El candidato a la presidencia por el partido de izquierda Unión Patriótica Jaime Pardo Leal, es asesinado en 1987 a causa de sus denuncias de las alianzas entre la clase política, el narcotráfico y el paramilitarismo. Quien lo reemplazó, Bernardo Jaramillo Ossa, cae asesinado en marzo de 1990. Luis Carlos Galán, candidato presidencial con opción de llegar al poder por parte del liberalismo, es asesinado por las Autodefensas Unidas de Colombia (AUC) el 18 de agosto de 1989; el 26 de abril de 1990 también es asesinado por las AUC el candidato a la presidencia Carlos Pizarro Leongómez, líder del denominado Movimiento M-19 recién amnistiado. En un periodo de tres años, fueron asesinados cuatro líderes políticos de primera línea y miles de militantes de la Unión Patriótica (UP).

Dargent y Muñoz proponen la hipótesis según la cual las políticas de descentralización, las reformas electorales y la constitución de 1991 que tuvo la intención de mejorar la calidad democrática, terminó por generar un proceso gradual de desinstitucionalización de los partidos tradicionales y su atomización ${ }^{14}$. Los problemas de desinstitucionalización aparecen desde los años setenta cuando los partidos tradicionales se reparten el poder por mitades y no existen opciones creíbles para terceras fuerzas; esta situación se ve agravada por las reformas introducidas por la nueva Constitución.

El proceso generado por la dilución de la diferenciación entre los partidos Liberal y Conservador, continúa y se agudiza luego de la promulgación de la Constitución del 91, la cual coadyuvó a la explosión de nuevos partidos, apertura que favoreció tanto a derecha como a izquierda y a las organizaciones étnicas regionales. La desinstitucionalización del sistema de partidos que transformó el sistema político colombiano (fragmentación del sistema de partidos) al romper el régimen bipartidista, tuvo como consecuencia no buscada el debilitamiento de los partidos tradicionales, lo cual resultó un fenómeno clave por cuanto constituyó una oportunidad para la emergencia de la nueva izquierda en Colombia, igual que ocurrió en otros países de América Latina, pero de forma tardía, a finales de los $90^{15}$.

La nueva Constitución de 1991, según el Observatorio Electoral para América Latina, dada su "ilimitada apertura", generó la atomización y explosión de auto candidaturas personalistas $^{16}$, introdujo importantes reformas institucionales a nivel electoral y del sistema de partidos, pero el sistema político no cambió sustantivamente, los partidos Liberal y Conservador continuaron teniendo el mayor ascendiente sobre la vida política, no obstante, la abstención, el clientelismo y el faccionalismo que ya habían empezado durante el Frente Nacional, no fueron suprimidos ${ }^{17}$.

\footnotetext{
${ }^{14}$ Eduardo Dargent, and Paula Muñoz, "Democracy against Parties? Party System De-Institutionalization in Colombia." Journal of Politics in Latin America, 3:2, 2011, 43-71.

15 Katrena Burgess and Steven Levitsky, "Explaining Populist Party Adaptation in Latin America: Environmental and Organizational Determinants of Party Change in Argentina, Mexico, Peru, and Venezuela", Comparative Political Studies, 2003, 36 (8), 881-911.

16 Véase Observatorio Electoral en 〈http://www.observatorioelectoral.org/biblioteca/?bookID=15\&page=10 > consultado 08/08/2015.

${ }^{17}$ Dieter Nohlen (ed.), Elections in the Americas, A data Handbook Vol. II South America, Oxford: Oxford University Press, 2005, 298.
} 
A partir de entonces, partidos y movimientos políticos adoptaron la táctica llamada “operación avispa" que generó la atomización de las listas ${ }^{18}$. A estos movimientos de corta duración basados en un representante político con nexos lejanos con los partidos tradicionales se les denominó "microempresas electorales", mecanismo utilizado por las nuevas fuerzas electorales independientes para adecuarse a las nuevas reglas y llegar a las corporaciones de elección popular con bajas votaciones y estrategias fragmentadas ${ }^{19}$.

De forma ascendente los colombianos se fueron distanciando de los partidos tradicionales a favor de grupos independientes y del abstencionismo. Ante la proliferación de partidos la reforma electoral del 2003 planteó la ampliación de los umbrales, implementación de listas y candidaturas únicas, ley de bancadas, voto preferente, cifra repartidora (D'hondt) y nuevas exigencias para la postulación de candidaturas; con el fin de eliminar los denominados "partidos de garaje" surgidos desde la nueva constitución.

A partir de los datos del cuerpo electoral elaborado por Jaramillo y Franco-Cuervo $(2005)^{20}$, el porcentaje de votantes respecto a los registrados por año en Colombia osciló bastante entre 1958, un año después de iniciado el Frente Nacional y el 2003. En 1958 votó el $69 \%$ de los registrados, de aquí en adelante ese porcentaje baja constantemente con algunos repuntes durante el Frente Nacional; los mayores bajones se registran en 1964 (36.9\%), 1968 (37.3\%), 1978 año en que finaliza el primer periodo el FN (33.4\%). Luego viene un periodo de casi diez (10) años en que esas cifras repuntan hasta alcanzar 54 y $55 \%$ para elecciones legislativas y baja para presidenciales. El mayor bajón se registra para 1990 a un año del Referendum para la aprobación de la nueva constitución de 1991 (21.5\%).

Según información del BID ${ }^{21}$, el total de escaños controlados por los partidos importantes al inicio y al final del periodo del estudio, Colombia aparece para 1978 con $97.49 \%$ a favor del Partido Conservador Colombiano y del Partido Liberal, 20 años después, para 1998, el porcentaje de escaños es de $69.56 \%$, esto es, hubo una disminución porcentual de $28.65 \%$ del total de escaños controlados por los dos partidos tradicionales. Esto muestra el resquebrajamiento del arraigo de estos dos partidos en la sociedad colombiana. Otras cifras basadas en encuestas muestran que el porcentaje de adherentes al Partido Liberal disminuyó del 44\% de la población en 1993 a 31\% en 2002 y los del Partido Conservador del 17\% al $12 \%$ en el mismo año; los simpatizantes de "otro partido" o de "ninguno" pasaron de $39 \%$ a

\footnotetext{
18 Práctica también conocida como transfuguismo. Esta práctica realizada por los liberales y conservadores que lideraban las otras listas tuvo importantes consecuencias prácticas como la distorsión del sistema electoral, sobre la efectividad y transparencia del conteo de votos sobre la publicación de los resultados.

${ }^{19}$ César Rodríguez Garavito, "La nueva izquierda colombiana: orígenes, características y perspectivas", En: Rodríguez Garavito César A. Barrett Patrick S., Chávez Daniel (Eds.), La nueva izquierda en América Latina. Sus orígenes y trayectoria futura, Bogotá, Grupo Editorial Norma, 2005, 199.

${ }^{20}$ Juan Jaramillo y Beatriz Franco-Cuervo, "Colombia" en: Nohlen Dieter (ed.), Elections in the Americas. A data Handbook, Vol. II South America, Oxford University Press, 2005.

${ }^{21}$ Banco Interamericano de Desarrollo, BID y el Instituto Internacional para la democracia y la Asistencia Electoral. J. Mark Payne (et. al.), La política importa. Democracia y desarrollo en América Latina, Washington D.C., 2003, 145-149.
} 
$57 \%^{22}$. El declive del Partido Conservador en Colombia y la falta de identidad con los partidos tradicionales generaron una multiplicación de partidos de izquierda, centro y derecha.

Otras variables relativas a la relación entre sistemas de partidos y gobernabilidad democrática, muestran esta desinstitucionalización de los partidos tradicionales, por ejemplo, respecto de la afinidad del público con los partidos políticos, Colombia aparece con una mayoría de $59.16 \%$ sin afinidad y una identificación con los partidos muy baja respecto de los otros países latinoamericanos. Otra variable como confianza en los partidos políticos disminuye entre 1996 y el 2001, siendo para Colombia una de las más bajas respecto del resto de la región latinoamericana (16.97\% en 2001). El porcentaje más bajo de toda la región se presenta respecto de la variable de percepción de las elecciones como limpias cuyo promedio para el periodo en estudio es de $19.85 \%$ siendo el promedio regional de $44.80 \%{ }^{23}$.

El Partido Social Conservador desapareció y surgió el Partido de la U (2002), Cambio Radical (1998) y partidos con nexos paramilitares como el Partido de Integración Nacional, PIN (2009). El socavamiento de los partidos favoreció el ascenso de políticos de derecha independientes con alta popularidad con discursos anti partido centrados en una figura personal como Álvaro Uribe Vélez en el 2002, reelegido en 2006 y por parte de la izquierda facilitó la elección de Luis Eduardo Garzón en el 2003 como alcalde de Bogotá, también con voto independiente. Esta crisis además de la incidencia normativa favoreció la unión de la izquierda legal.

El Frente Social y Político de izquierda ya desaparecido fue creado en 1999 con el objetivo de presentarse a elecciones en el siguiente año y en el 2002; inició como una coalición política de izquierda en la que participaron: el Partido Comunista Colombiano (que nació en 1934), los sobrevivientes de la Unión Patriótica, Presentes por el Socialismo, Poder Unido Popular, Colectivo Sindical Guillermo Marín, el Movimiento por la Defensa de los Derechos del Pueblo y otras organizaciones sociales y sindicales. Se une en 2005 a la coalición Alternativa Democrática. Alternativa Democrática fue una coalición de izquierda conformada por movimientos sociales de izquierda como el Frente Social y Político, el Movimiento Obrero Independiente y Revolucionario, MOIR, Unidad Democrática, Movimiento Ciudadano, Autoridades Indígenas de Colombia y Opción Siete, liderada por el ex magistrado Carlos Gaviria Díaz, la cual conformó en el 2005 junto con el Polo Democrático Independiente el llamado hoy Polo Democrático Alternativo. En el año electoral 2002 varios sectores de izquierda decidieron conformar el llamado Polo Democrático el cual lanzaría la candidatura presidencial del ex sindicalista Luis Eduardo Garzón.

\footnotetext{
${ }^{22}$ Rodríguez, Ibid, 199.

${ }^{23}$ BID, Ibid, 146-149.
} 
Entre la década del 70 hasta el 2003 fueron creados 104 partidos, movimientos y alianzas distintas. La mayoría de los nuevos partidos, movimientos y alianzas participaron en un rango de cero a una elección presidencial, cero 45 de ellos, una elección 14 de ellos, dos elecciones 3 de ellos, tres elecciones 2 de ellos, cuatro elecciones sólo uno ${ }^{24}$.

Como muestra la Tabla 1, las fuerzas políticas distintas a las tradicionales van en permanente crecimiento hasta llegar a ser mayoría. En Colombia fue claro que el rompimiento del bipartidismo dio lugar a la expresión de sectores más inclinados hacia la derecha (Partido de la U, Centro Democrático) tanto como a sectores de izquierda (Polo Democrático), con lo cual en apariencia emerge una polarización entre izquierda y derecha.

Tabla 1. Colombia - elecciones parlamentarias (representantes a la cámara) años 1962, 1970, 1990, 1998 y 2002.

\begin{tabular}{|c|c|c|c|c|c|}
\hline Año & $\mathbf{1 9 6 2}$ & $\mathbf{1 9 7 0}$ & $\mathbf{1 9 9 0}$ & $\mathbf{1 9 9 8}$ & $\mathbf{2 0 0 2}$ \\
\hline PL & 54.6 & 51.3 & 59.2 & 50.0 & 29.1 \\
\hline PC & 45.4 & 48.7 & 31.3 & $15.1^{* *}$ & 10.8 \\
\hline Otros $^{*}$ & 3.9 & 0.2 & 9.5 & 35.4 & $60.1^{* * *}$ \\
\hline
\end{tabular}

*En otros se suman todos los demás que no pertenecen a los partidos tradicionales (incluido el ítem otros del cuadro fuente). **En 1998 el PC se denomina Partido Social Conservador. En ese mismo año en otros hay 39 partidos y varias coaliciones. ***En el 2002 los votos de los demás partidos se reparten el resto de la votación que ya no pertenece a los dos partidos tradicionales. Fuente: Nohlen Dieter (ed.), Elections in the Americas. A data Handbook. Vol. II South America, Oxford University Press, 2005. Tomado del cuadro 2.7 Parlamentary Elections Lower Chamber 1931-2002, 324-330.

Sin embargo, la tendencia al multipartidismo fue la forma que adquirió la reorganización de los mismos partidos tradicionales de derecha que se alinderaron alrededor del Partido de la U, Cambio Radical, PIN y varios otros ${ }^{25}$. El líder del Partido de la U, salió de las toldas del liberalismo, pero representaba el pensamiento más auténtico del extinto Partido Conservador, Cambio Radical también emergió del Partido Liberal y el PIN está constituido por reductos de paramilitarismo, no obstante los partidos tradicionales continúan figurando como tales, pero, empieza a existir una polarización que ya no es entre el Partido Liberal y el Partido Conservador, sino que parece tener una configuración distinta de la relación entre los poderes políticos ${ }^{26}$.

Con la erosión de los partidos tradicionales, las terceras fuerzas ganaron en casi la mitad de los municipios colombianos entre 1988 y 1997, en varias ciudades intermedias y grandes ciudades. Esta crisis tuvo consecuencias que sólo hasta finales de la década del 90 y

\footnotetext{
${ }^{24}$ Nohlen, Ibid, 312, 316.

${ }^{25}$ Entrevista con el senador del Polo Democrático Alternativo, PDA, Jorge Robledo el 14 de abril de 2016.

26 Véase artículo de Manuel Alcántara Sáenz y Flavia Freidenberg, 2001, 27 "Los partidos políticos en América Latina" en

<http://americo.usal.es/oir/opal/pdfs/Manuel_alcantara/ALHvol27alcantarafreidenberg.pdf> consultado 01/08/2017.
} 
comienzos de la siguiente, dio posibilidades a la izquierda de reorganización en un nuevo partido.

\section{Reformas políticas}

Las reformas políticas o cambios en las reglas del juego electoral, otorgan ventajas o desventajas a los participantes en las contiendas electorales ${ }^{27}$ y afectan a los partidos de diversas formas. La crisis de los partidos tradicionales fue también una consecuencia de estas reformas. Esto es, las reformas no sólo deben verse como un factor coadyuvante del éxito de la perduración de los partidos sino como una causa de su debilitamiento o extinción y en consecuencia también como favorecedoras de la tendencia personalista de algunos líderes.

Desde el punto de vista institucional formal, el comportamiento electoral entre los 80 y el 2010 en Colombia está determinado por una serie de reformas importantes: 1) la reforma de elección popular de alcaldes en 1986, 2) la elección popular de gobernadores en 1991, 3) la expedición de la Constitución de 1991, 4) la reforma política de 2003 y; 5) las reformas políticas posteriores, 2005, reelección y Ley de bancadas $^{28}$, la reforma constitucional de 2009 y Ley de Partidos y Movimientos de $2011^{29}$. Las tres primeras hacen parte del proyecto de democracia participativa que se desprende de la Constitución de 1991. A continuación, se señalan las reformas que incidieron en mayor medida sobre el comportamiento electoral de los partidos, en particular sobre los partidos de izquierda democrática.

\section{La Constitución de 1991 y la reforma de 2003}

Antes de la reforma de 2003 obtener una personería jurídica para los partidos resultaba un ejercicio sencillo igual que otorgar avales a distintos candidatos, ello provocó la fraccionalización del sistema de partidos. La constitución del 91 había dado paso a la entrada de nuevas fuerzas políticas para la representación nacional que incluyó a dos senadores por las comunidades indígenas (circunscripción indígena), en suma, se abrió el espacio a nuevos competidores: nuevos partidos, nuevos movimientos y candidatos independientes. Pero las listas y candidatos se incrementaron y emergieron nuevos movimientos políticos que se salieron de las directrices de los partidos tradicionales; algunos señalan la cifra de 70 partidos con personería jurídica que emergieron y desaparecieron y presentaron listas tanto a nivel nacional como regional. Los partidos

\footnotetext{
27 Según Camilo Vargas, las reformas electorales de 1991 se fundan en el espíritu de ruptura con el bipartidismo establecido desde el Frente Nacional para dar cabida a nuevas fuerzas distintas de los partidos tradicionales Liberal y Conservador. Entrevista con Camilo Vargas, internacionalista, politólogo, máster en sociología política, analista de la Misión de Observación Electoral, MOE, el 15 de diciembre 2015.

${ }^{28}$ Mediante el Acto Legislativo 02 de 2004 se permite por una sola vez la reelección presidencial.

${ }^{29}$ Ley Estatutaria de partidos 1475 de 2011.
} 
tradicionales dejaron de monopolizar la competencia y perdieron éxito electoral ${ }^{30}$. Se creó mayor competencia, pero se incrementó la fraccionalización y la volatilidad. Hacia el 2002 llega por primera vez en la historia a la presidencia un candidato no perteneciente a ninguno de los partidos tradicionales, se había incrementado el número de partidos de tres [3] en 1991 a nueve [9] en 2002 y la nueva izquierda empezaba a descollar. Antonio Navarro, Carlos Gaviria y Jaime Dussan líderes de la izquierda estuvieron entre las más altas votaciones para el Senado. Antonio Navarro concentró su votación en Bogotá donde fue representante a la cámara entre 1998 y 2002 y en su región natal, el departamento de Nariño, donde fue alcalde por su capital, la ciudad de Pasto entre 1995 y 1997; Dussan concentró su votación en el magisterio (Federación Colombiana de Educadores, FECODE). Carlos Gaviria como candidato de izquierda en 2006 obtuvo la segunda más alta votación luego de Álvaro Uribe Vélez quien fuera reelecto. La Constitución de 1991 permitió la emergencia de sectores políticos distintos de los partidos tradicionales y al menos formalmente rompió el bipartidismo, pero el exceso de partidos representados en el Congreso incrementó el personalismo, lo cual provocó la contrarreforma de $2003^{31}$.

La reforma política de 2003 buscó controlar la fragmentación partidaria derivada de la nueva constitución mediante incentivos a partidos y movimientos políticos existentes para que presentaran listas únicas, incentivó la cohesión de los partidos y favoreció las votaciones más altas. Esta norma favoreció la creación del partido de nueva izquierda Polo Democrático Independiente (PDI), el cual crearía junto a otras fuerzas, el Polo Democrático Alternativo (PDA) y a la vez permitió la creación del Partido Social de Unidad Nacional (PSUN) de derecha, disidencia del Partido Liberal Colombiano, que apoyaría la reelección de Álvaro Uribe Vélez en $2006^{32}$.

La reforma se aprueba durante el primer gobierno de Álvaro Uribe Vélez mediante el acto legislativo 01 de 2003. Los cambios generados tuvieron que ver con la forma como son elegidos los parlamentarios, la composición del Congreso y el funcionamiento de los partidos. En el primer caso introdujo la cifra repartidora que reemplaza el sistema de cociente y residuo, el cual fortalece las listas ya fuertes a través del requisito del umbral para el otorgamiento de personería jurídica. En relación a los partidos, se introdujo la lista única, lo que fortaleció a los partidos y cada partido debió organizar el orden de los candidatos de las listas. Cada candidato tenía la opción de ser elegido sólo si lograba entrar a la lista de un partido importante; los partidos debían volver a convertirse en los principales actores del ámbito político; pero la reforma también permitió que por medio del voto preferente los candidatos del mismo partido se enfrentaran entre sí, lo cual iba en contravía de su propio fortalecimiento ${ }^{33}$.

\footnotetext{
${ }^{30}$ Batlle y Puyana, Ibid, 75, 76.

${ }^{31}$ Vargas, Ibidem.

${ }^{32}$ Batlle y Puyana, Ibid, 76.

33 Carlos Eduardo Gechem Sarmiento, El congreso colombiano a partir de 1991, Bogotá, Colombia, Universidad Externado de Colombia, Instituto de Estudios Constitucionales Carlos Restrepo Piedrahíta, Temas de Derecho Público No 73, 2005, 113-115.
} 
La reforma de 2003 se centró en lista única, umbral y financiación, prohibió la doble militancia, incluyó un umbral electoral del 2\% que cambió la exigencia de 50.000 firmas o votos como aparecía en la Constitución del 91 . El $2 \%$ de votos válidos fue una alta exigencia a la conformación de partidos y movimientos, con la intención de incentivar la reagrupación de partidos y de evitar su dispersión lo cual colocaba un bastón más alto a la sobrevivencia política. El cambio de la fórmula electoral del método de cocientes y residuos por el método D’Hondt le otorgó mayor proporcionalidad al sistema, castigó la atomización y premió la reagrupación ${ }^{34}$. El efecto sobre la derecha fue la recomposición de los partidos tradicionales y su reorganización en dos grandes partidos tradicionales (Liberal y Conservador) y tres grandes partidos de candidatos presidenciables (Partido de la U, Cambio Radical y Centro Democrático), ello permitió el control de sus militantes; los partidos de la U y Cambio Radical son alianzas de políticos del centro del país donde se concentra la votación de la presidencia con políticos de las regiones periféricas donde se concentra la votación al congreso (alianza de presidenciables con los gamonales regionales); las mayores votaciones del Partido de la U se focalizan en Córdoba, Sucre y Valle, mientras las mayores votaciones de Cambio Radical lo hacen en La Guajira, Magdalena y Bolívar. El Centro Democrático tiene el mismo esquema de cooperación de un presidenciable (Uribe) con gamonales regionales, los cuales son en realidad los grandes electores. Mientras la derecha ha sabido ganar elecciones, la izquierda en cambio no está acostumbrada a hacer política en las regiones mediante lo que se ha dado en llamar en Colombia "la politiquería" (demagogia, promesas falsas, engaño, etc.) y además es proclive a la atomización ${ }^{35}$.

El efecto de la reforma de 2003 sobre la izquierda consiste en obligar a sus distintas facciones a la reunificación en un solo partido después de una gran dispersión en los años 90. En suma, la presión normativa obligó a los diversos grupos de izquierda a unirse igual que al resto de partidos, si pretendían competir electoralmente con alguna eficacia. Pero la izquierda se fortaleció en ciudades grandes, sin llegar a los municipios, en particular los más pequeños, donde no tenía mucha presencia. El Polo Democrático Independiente, PDI, el M-19, el Movimiento Ciudadano y el Movimiento Verde Oxígeno (ya extintos), triunfaron en Cali, Bogotá y Barranquilla, pero no lograron expandirse a todo el territorio nacional, mientras el fortalecimiento del voto de opinión se demostró con el triunfo del PDI en Bogotá ${ }^{36}$. De manera que el espacio político de las regiones y localidades alejadas de las ciudades quedó sólo en manos de los nuevos partidos de derecha derivados de los

\footnotetext{
34 María Eugenia Correa Olarte y Nicolás Cañón Murillo, Análisis comparativo de las elecciones presidenciales y de Congreso de 2002 y 2006 y de los partidos políticos en relación con el impacto de la reforma política de 2003, Bogotá, Colombia, Universidad Gran Colombia, Ediciones Grancolombianas, 2008, 52.

${ }^{35}$ Como muchas izquierdas, la izquierda colombiana surge de organizaciones que no nacieron a partir de la práctica electoral sino de otro tipo de actividades como la lucha sindical, la movilización social, etc. En cambio, la derecha y los militantes de derecha se reúnen en torno a intereses cuyo alcance depende de saber jugar en el campo electoral, son profesionales de la política acostumbrados a ganar elecciones. La izquierda cuenta con muy pocos profesionales de este tipo (Vargas, Ibidem).

${ }^{36}$ Hoskin y García, Ibid, 84 y 88.
} 
tradicionales Liberal y Conservador que apoyaron al uribismo desde lo local como "Cambio Radical" y el Partido de La U.

El resultado fue la diversificación de los partidos en los municipios pequeños donde emergieron candidaturas independientes y partidos nuevos ${ }^{37}$ lo cual favoreció el fortalecimiento de la corriente independiente del uribismo ${ }^{38}$.

La principal consecuencia de este nuevo método de elección para el caso de los partidos fuertes es la obtención de un mayor número de curules y para partidos débiles electoralmente implicó que aquellos que no obtenían ninguna curul por cociente electoral, la obtuvieran por medio de la cifra repartidora. Pese a la reagrupación de los partidos, el personalismo continúa por la introducción de la figura del voto preferente ${ }^{39}$. Sin embargo, aunque la reforma terminó con la llamada "operación avispa"40 y redujo el número de partidos con personería jurídica, para las elecciones legislativas del 2006, el Número Efectivo de Partidos (NEP) siguió siendo muy alto ${ }^{41}$. Por otro lado, la financiación de las campañas se incrementó en un $300 \%$ para el 2006, lo que dio una ventaja comparativa a la clase política tradicional que estaba ya en Senado y Cámara ${ }^{42}$.

Una de las condiciones que acompañaron el ejercicio eleccionario en el 2003, fue la abstención, el 13\% de los municipios registraron una participación inferior al 50\%, en el año 2000 la participación fue del 11\%, en los 90 había sido superior al 25\%, lo anterior significa que durante diez [10] años en más de una cuarta parte del país, votaron menos de la mitad de personas registradas en el censo electoral. La reforma de 2003 tampoco morigeró los problemas relativos a las garantías electorales: en el 15\% de los municipios del país no fue posible ejercer el derecho a elegir y ser elegido, hubo candidaturas únicas para alcaldías, amenazas a candidatos y partidos políticos y no se pudieron celebrar elecciones en once [11] municipios donde no se inscribieron candidatos debido al orden público $^{43}$.

\section{Acto Legislativo 02 de 2004}

Esta reforma tuvo como resultado un desequilibrio en el diseño constitucional de 1991, mediante ella se aprobó la reelección presidencial para el periodo 2006-2010; dicha reforma

\footnotetext{
${ }^{37}$ Para el 2003 se presentaron 3.256 candidatos a alcaldías en todo el territorio nacional y en el 2000 se habían presentado 3.379, la fórmula de agregación fue más efectiva para Senado y Cámara.

${ }^{38}$ Ibidem, 88.

${ }^{39} \mathrm{El}$ voto preferente se da cuando el movimiento o partido político inscribe una lista abierta, el elector vota por ésta pero además por alguno de los candidatos de la lista. Logran curul los candidatos con más votos de acuerdo con el número de escaños que obtenga el partido sin que importe el orden de la lista.

40 Estrategia utilizada por los partidos tradicionales de otorgamiento indiscriminado de avales para la inscripción de múltiples listas en todo el país por circunscripción con el objetivo de ampliar su presencia en todo el territorio y su representación en el Congreso.

${ }^{41}$ Batlle y Puyana, Ibid, 77.

${ }^{42}$ Hoskin y García, Ibid, 61,80.

${ }^{43}$ Hoskin y García, Ibid, 81, 103.
} 
generó un efecto de polarización de la arena política del país. Pese a que fue planteada con base en el amplio respaldo al presidente Álvaro Uribe Vélez ${ }^{44}$. La reforma fue objetada por la izquierda (PDA). El proceso de reforma estuvo salpicado de polémicas sobre su legitimidad y legalidad y escándalos acerca de la transparencia en la votación en el Congreso. La llamada "yidispolítica" fue el escándalo que explotó en 2008 con base en las declaraciones de la representante a la Cámara Yidis Medina quien admitió haber recibido dádivas por parte de funcionarios del gobierno, a cambio de su voto favorable a la reforma que permitía la reelección inmediata del presidente ${ }^{45}$. Así los resultados positivos de la reforma de 2003 respecto del reagrupamiento de la nueva izquierda, fue anulado por esta reforma de 2004 que tuvo un candidato claramente favorecido (Álvaro Uribe).

\section{Reforma de 2009}

La reforma expedida por medio del Acto Legislativo 01 de 2009 suspende de manera temporal la prohibición de la doble militancia e incluye elementos para el proceso electoral del 2010 y busca responder ante el escándalo de la parapolítica por la infiltración del poder paramilitar en el poder legislativo ${ }^{46}$. Castro apunta que, por un lado, el gobierno buscó adaptar el sistema electoral y de partido a sus intereses particulares y, por otro, responder a demandas de sectores democráticos, lo cual la hace ambivalente. Se incluye la opción de voto preferente y la figura de "silla vacía" según la cual los partidos y movimientos políticos no pueden sustituir con otro candidato de la lista a los que hayan sido condenados por delitos específicamente señalados (el escaño queda vacío); se incrementa el umbral al $3 \%$ para participar en la repartición de escaños en circunscripciones plurinominales desde el 2014; se estableció que miembros de un partido que se presenten a elección por un partido distinto, deben renunciar con un año de anticipación a su curul. Además, los partidos políticos serán sancionados con multas, devolución de recursos dados por el Estado para campañas y pérdida de personería jurídica en casos en que se avalen candidatos que fueran condenados por delitos de lesa humanidad, vínculos con grupos armados ilegales, narcotráfico y delitos contra mecanismos de participación democrática ${ }^{47}$. La elevación del umbral electoral afectó negativamente a los partidos más pequeños y a líderes independientes que debieron buscar avales en partidos de distinta índole, lo cual generó el fenómeno denominado "feria de avales".

\footnotetext{
${ }^{44}$ Correa y Cañón, Ibid, 55.

${ }^{45}$ Periódico eltiempo.com, 15 de abril de 2015.

${ }^{46}$ Santiago José Castro Agudelo, Del dicho al hecho: reformas políticas y sistema de partidos en Colombia 2002-2010. Transformaciones en el sistema de partidos en Colombia a partir de las reformas políticas de 2003 y 2009 y la reelección presidencial, Bogotá, Institución Universitaria Politécnico Grancolombiano, 2012.

${ }^{47}$ Batlle y Puyana, Ibid, 78.
} 


\section{Reforma de 2011 (Ley de Partidos No 1475)}

Mediante esta reforma se desarrollan disposiciones frente al sistema electoral, el funcionamiento interno de los partidos y movimientos, el régimen de responsabilidad de éstos, de sus directivas y el financiamiento de partidos, movimientos y de las campañas.

Esta reforma amplía las causales de doble militancia, reglamenta las consultas internas e inter partidarias y sanciones en caso de que sus resultados no sean acatados, se establecen procedimientos y requisitos de disolución, liquidación, fusión y escisión voluntaria. Se otorga poder al Consejo Nacional Electoral, CNE, para ordenar disolución y liquidación de partidos y movimientos que utilicen o permitan utilizar la violencia para el ejercicio de la participación política y electoral, en especial, se reglamenta la responsabilidad sobre el otorgamiento de avales. Sobre financiación se establecen criterios de distribución y el peso de cada uno en el presupuesto total del partido; la reforma también obliga a los partidos y movimientos a presentar informes contables al CNE. Establece que las campañas electorales pueden ser financiadas con recursos públicos y privados y se considera el otorgamiento de anticipos ${ }^{48}$.

\section{Consecuencias prácticas de las reformas}

Las reformas favorecieron partidos nuevos pero grandes, que contaron con personería jurídica, como el PSUN por la derecha y el PDA por la izquierda, pero condenaron a los partidos nuevos pequeños sin personería jurídica o que la perdieron en el curso de escisiones como en el caso de Progresistas y del PTC que salieron del PDA. Para estos casos el mecanismo causal de su falta de fuerza en las regiones se sostiene en las consecuencias prácticas de la reforma política, no es así para el caso del PDA que cuenta con personería jurídica.

Según la Tabla 2 los partidos más exitosos siguen siendo los terceros partidos escindidos de los partidos tradicionales Liberal y Conservador (PSUN) seguido por estos (PCC y PLC), en dos elecciones que ya están condicionadas por las reformas. El PDA aparece rezagado en sexto lugar, superado por el nuevo Partido Verde, que es visto como una opción más centrista.

Tabla 2. Éxito electoral, elecciones legislativas 2010 y subnacionales 2011.

\begin{tabular}{|c|c|c|c|c|c|}
\hline Partido & Alcaldías & $\begin{array}{c}\text { Escaños en } \\
\text { Concejos }\end{array}$ & Gobernaciones & $\begin{array}{l}\text { Escaños en } \\
\text { Asambleas }\end{array}$ & $\begin{array}{c}\text { Escaños en legislativas } \\
\text { (Senado y Cámara) }\end{array}$ \\
\hline $\begin{array}{l}\text { Partido Social de } \\
\text { Unidad Nacional, } \\
\text { PSUN }\end{array}$ & 258 & 2.054 & 4 & 74 & $28 / 48$ \\
\hline $\begin{array}{l}\text { Partido Conservador } \\
\text { Colombiano, PCC }\end{array}$ & 194 & 1.989 & 1 & 65 & $22 / 36$ \\
\hline Partido Liberal & 181 & 1.873 & 6 & 78 & $17 / 38$ \\
\hline
\end{tabular}




\begin{tabular}{|l|c|c|c|c|c|}
\hline Colombiano, PLC & & & & & $8 / 16$ \\
\hline Cambio Radical, CR & 155 & 1.448 & 1 & 50 & $5 / 3$ \\
\hline Partido Verde, PV & 49 & 717 & 2 & 23 & $8 / 5$ \\
\hline $\begin{array}{l}\text { Polo Democrático } \\
\text { Alternativo, PDA }\end{array}$ & 9 & 231 & 0 & 7 & $3 / 1$ \\
\hline $\begin{array}{l}\text { Movimiento } \\
\text { Independiente de } \\
\begin{array}{l}\text { Renovación } \\
\text { Absoluta, MIRA }\end{array}\end{array}$ & 1 & 45 & 1 & 7 & $\mathrm{NA}$ \\
\hline $\begin{array}{l}\text { Grupo Significativo } \\
\text { de Ciudadanos, GSC }\end{array}$ & 163 & 750 & 14 & 17 & $11 / 18$ \\
\hline Otros & 66 & 846 & 3 & 16 & \\
\hline
\end{tabular}

Fuente: Batlle y Puyana 2013:80

La salida del sector petrista del PDA en 2010 (partidarios de Gustavo Petro) el cual dio lugar a la emergencia del movimiento Progresistas, tuvo diversos problemas de ésta índole al perder su personería jurídica, por lo cual el candidato Gustavo Petro debió presentarse "por firmas", mecanismo que se denomina "Movimiento Significativo de Ciudadanos", establecido para aquellos que aspiren a presentarse y que no cuenten con dicho requisito ${ }^{49}$. Para ello se requiere una cierta cantidad de firmas, luego de lo cual se presentan ante la Registraduría Nacional del Estado Civil para dar a conocer su movimiento y el objeto del mismo, cuya meta es presentar uno o varios candidatos a cualquier corporación y circunscripción. La REC obliga a recolectar 50.000 firmas en los formularios suministrados por ésta, con el fin de legitimar la directiva del movimiento ${ }^{50}$. Cualquier error detectado por los grafólogos provoca la anulación total de la hoja de firmas. Una vez surtido este proceso, la Registraduría aprueba el Comité de Movimiento Significativo de Ciudadanos para el impulso de la candidatura de que se trate. Este fue el proceso que debió surtir la candidatura de Petro a la alcaldía de Bogotá, el cual requirió 50.000 firmas, para lo que debió recabarse 300.000 con el objeto de respaldar las posibles anulaciones. Este procedimiento requiere recursos tanto humanos como financieros y puede llegar a tener

\footnotetext{
49 "De acuerdo con la Ley 130 de 1994 existen en la actualidad dos modalidades para que los candidatos se inscriban para las elecciones que se realizarán en el país en el 2014: con el aval de un partido o movimiento político con personería jurídica reconocida por el Consejo Nacional Electoral, o por medio de Grupos Significativos de Ciudadanos. Esta segunda opción establece que quienes no cuentan o no desean el aval de un movimiento o partido político, o prefieren crear su propio grupo político, puedan hacerlo y aspirar a una curul cumpliendo con los requisitos que estipula la ley para garantizar a los colombianos diversidad de candidatos y programas políticos."De acuerdo con el artículo 9 de la Ley 130 de 1994, los grupos significativos de ciudadanos que postulen candidatos deberán reunir un número de firmas válidas equivalentes al menos al $20 \%$ del resultado de dividir el número de ciudadanos aptos para votar en la respectiva circunscripción electoral entre el número de curules o cargos a proveer. En todo caso, el máximo de firmas a exigir para inscribir un candidato asciende a 50.000. Esto significa que para el caso de candidatos al Senado se deben reunir 50.000 firmas, mientras que los representantes a la Cámara deben sumar apoyos equivalentes al 20\% del resultado de dividir el censo electoral del departamento entre el número de curules de dicha corporación". Registraduría Nacional del Estado Civil en $<$ http://www.registraduria.gov.co/Nuevas-reglas-enla-inscripcion.html> consultado 02/02/2016.

${ }^{50} \mathrm{El}$ número de firmas requeridas depende del censo electoral, en un municipio pequeño se requieren menos firmas.
} 
tanto costo como la propia campaña política ${ }^{51}$. Tal mecanismo puede ser utilizado por cualquier movimiento, como fue el caso del candidato elegido para la alcaldía de Bogotá en 2015, Enrique Peñalosa, quien se presentó "por firmas" por el movimiento "Equipo por Bogotá". El procedimiento hace las veces de una especie de campaña previa, dado que debe hacerse como mínimo con un año de antelación. En las elecciones de 2011 hubo una expansión de la presentación de candidaturas por firmas, lo que ha vuelto a incidir sobre la cantidad de partidos y movimientos.

La recolección de firmas debe hacerse para la candidatura a la alcaldía y por aparte para Consejo y para cada una de las Juntas Administradoras Locales, JAL (20 en el caso de Bogotá). Cuando se van a inscribir las candidaturas a las alcaldías luego de la recolección de firmas, el movimiento debe contar con una garantía económica, en contraprestación a los gastos que el Estado asume al aceptar la candidatura ${ }^{52}$, por tanto, se asegura de que la candidatura sea presentada efectivamente. Ese respaldo es necesario para cada uno de los candidatos a cada una de las corporaciones públicas (incluidas las Asambleas en los departamentos). La cantidad de dinero de la garantía depende del tipo de circunscripción.

En el caso de Bogotá puede ascender a 200 millones de pesos aproximadamente, para lo cual se deja hipotecado en la compañía de seguros un bien que respalde el monto total en dinero. Estos movimientos políticos deben comprar una póliza a una compañía de seguros por la cantidad correspondiente. Además el partido requiere pasar el umbral equivalente al $3 \%$ del total de la votación de la respectiva circunscripción electoral ${ }^{53}$.

Dado el prestigio de Gustavo Petro como senador, fue posible su elección bajo estas condiciones, pero no lo fue, llevar a cabo este proceso en otras regiones y localidades del país aun contando con militancia y simpatizantes en todos los departamentos para la recolección de firmas. Por tanto, el obstáculo fundamental a la creación de un movimiento de carácter nacional como el petrismo, provino de un aspecto puramente pragmático: los costos que una compañía de seguros debería asumir para cubrir los 1.100 municipios del país con personal especializado en peritaje de bienes, capaz de llegar incluso a los municipios más apartados del país. Las compañías de seguros no estuvieron dispuestas a asumir este costo que les implicaba renunciar a sus ganancias e ir a pérdida.

\footnotetext{
${ }^{51}$ Por la ccontratación de personas para la recolección de firmas. En este ejercicio se presentan diversos problemas prácticos como colocación de números de cédula falsos por parte de los ciudadanos, dado que éstos tienen la creencia de que la firma lo compromete políticamente cuando en realidad sólo expresa que el ciudadano respalda que el candidato de que se trate pueda competir en la arena electoral.

52 El otro requisito para los candidatos sin partido es el establecimiento de una "póliza de seriedad" de la candidatura “...la cual debe tener una vigencia de seis meses después de la declaratoria de los resultados de las elecciones por la autoridad electoral competente. El Consejo Nacional Electoral fijará el monto de la cuantía de la póliza" en <http://www.registraduria.gov.co/rev_electro/articulos/recoger.htm> consultado $02 / 02 / 2016$

53 Entrevista con Jorge Charry, directivo del Partido de los Trabajadores de Colombia, PTC, vocero del movimiento Progresistas, Alianza Verde 14 y15 de enero de 2016.
} 
En acto político de agradecimiento al ex concejal Yezid García del Partido Verde, llevado a cabo el viernes 22 de enero de 2016 en Bogotá, al cual asistieron líderes del PDA como de Progresistas-Alianza Verde, dos de los discursos hicieron alusión a las restricciones creadas por la actual normativa electoral para la izquierda colombiana distinta del PDA. Gustavo Petro y Marcelo Torres, cada uno desde una perspectiva distinta criticaron las consecuencias prácticas de esta reforma. Según Marcelo Torres, ha provocado que la unidad de la izquierda se haya dado "con fórceps", por una simple victoria electoral: "El cociente electoral lo inventó la revolución francesa, fue el producto de una revolución, por qué va a ser mejor el umbral y la cifra repartidora", "Es la hora de que haya un régimen electoral que no sea excluyente para quienes no controlan los factores que definen las elecciones en Colombia: los medios, la plata, las posiciones a las que difícilmente se puede acceder ..." ${ }^{54}$.

Por su parte Gustavo Petro, criticó el hecho de que la nueva normativa haya causado dispersión política y el afán por obtener un aval:

"Lo que hemos presenciado desde hace varios años es que ese tipo de normatividad ha producido una dispersión de las fuerzas progresistas y democráticas (....) el afán a último momento de ver [sic] en dónde me meto para poder ser un candidato, ha hecho que sectores del progresismo y de la democracia colombiana estén en el Partido Liberal unos y otros en la ASI y otros en el Partido Verde y otros en el Polo y otros buscan firmas como nosotros y otros en el MAIS, etc., y si viene otra elección bajo esas mismas condiciones, aumentará la dispersión y es una cosa que en el caso de Bogotá con Clara López al final fue determinante, porque no estábamos unidos, ahí cada fuerza fue reaccionando primero fue probando etc., $\mathrm{y}$ fue perdiendo unos tiempos vitales mientras que la candidatura de Peñalosa iba aglutinando la derecha, al uribismo y al vargasllerismo, juntos hicieron la mayoría que hoy gobierna ${ }^{55}$.

\section{Conclusiones}

Desde el punto de vista teórico, es claro que las reformas electorales en el caso de Colombia, en realidad tuvieron efectos importantes en la creación y desaparición de partidos políticos tanto de izquierda como de derecha, dichas reformas fueron intencionales, obedecieron a una preocupación expresa sobre la necesidad de abrir nuevos espacios a nuevos partidos (Constitución de 1991), a la de eliminar la proliferación de partidos políticos "de garaje" (reforma de 2003), la de favorecer la reelección inmediata de Álvaro Uribe (Acto Legislativo 02 de 2004), etc., por tanto, no se aplica a rajatabla la hipótesis de Levitsky, Loxton y Van Dyck sobre el limitado impacto del diseño institucional sobre los resultados de construcción de partidos. Respecto de su planteamiento acerca del centrismo del conflicto para la conformación de partidos fuertes, es un hecho que los partidos tradicionales en Colombia lograron su perdurabilidad a través de la violencia,

\footnotetext{
${ }^{54}$ Discurso del líder del PTC, Marcelo Torres, el 22 de enero de 2016.

${ }^{55}$ Discurso del líder de Progresistas, Gustavo Petro, el 22 de enero de 2016.
} 
no obstante, también lo fue que la perdieran a través del régimen consocionalista y de las nuevas reglas del juego generadas por la Constitución de 1991.

La normativa actual es considerada claramente antidemocrática por los sectores de la izquierda. En la práctica los dos mecanismos señalados (firmas y garantía económica) significan para los partidos pequeños sin personería jurídica, obstáculos de carácter excluyente $\mathrm{y}$, por ende, son vistos como factores que atentan contra la participación de los partidos nuevos pequeños y con poca capacidad económica. No obstante, los partidos grandes o pequeños que cuenten con personería jurídica pueden presentar candidatos en cualquier parte del país y tienen derecho a una subvención estatal para sostener el partido y además es un incentivo para evitar la división de los partidos tradicionales y de los partidos grandes derivados de éstos, dado que impide al menos en la teoría, la creación masiva de partidos locales ${ }^{56}$. Lo anterior significa que la reforma de 2011 favorece a los partidos más grandes y con personería y desfavorece a los pequeños sin personería, esto es, la izquierda con personería tendrá ventaja sobre la izquierda sin personería para expandirse hacia regiones y municipios más alejados del centro, lo que no significa que sea determinante en dicha expansión ${ }^{57}$.

La reforma política propuesta por el gobierno para respaldar la Justicia Especial para la Paz, JEP y las llamadas circunscripciones especiales de paz, provenientes de los recién firmados acuerdos de paz en La Habana, Cuba, para facilitar la incorporación de las FARCEP a la arena electoral, fue hundida por la oposición conservadora y el uribismo en el Congreso de la República. El hundimiento de esta reforma que en su versión inicial fue defendida por varios de los partidos minoritarios de oposición: Alianza Verde, PDA, MAIS, incluso MIRA y Opción Ciudadana, pudo obedecer al hecho de que favorecía a la oposición de izquierda mediante la eliminación de las listas cerradas y la disminución del umbral electoral, claves para tener posibilidades de competitividad en la arena electoral y para construir partido, lo cual sigue dejando en desventaja a los partidos alternativos ${ }^{58}$.

\section{Referencias bibliográficas}

\section{Libros y artículos}

Banco Interamericano de Desarrollo, BID y el Instituto Internacional para la democracia y la Asistencia Electoral. J. Mark Payne (et. al.). La política importa. Democracia y desarrollo en América Latina. Washington D.C., 2003.

\footnotetext{
${ }^{56}$ Charry, Ibidem.

57 La izquierda en Colombia no es un solo bloque y se hace necesario a partir de 2010 hacer esta diferenciación.

${ }^{58}$ Revista semana.com 1 de agosto de 2017.
} 
Batlle Margarita y Puyana José Ricardo, "Reformas políticas y partidos en Colombia: cuando el cambio es la regla". Politai, Revista de Ciencia Política, Año 4, Segundo Semestre No 7, 2013,7388 .

Burgess, K., and Levitsky, S.,"Explaining Populist Party Adaptation in Latin America: Environmental and Organizational Determinants of Party Change in Argentina, Mexico, Peru, and Venezuela”. Comparative Political Studies , 2003, 36 (8), 881-911.

Castro Agudelo Santiago José. Del dicho al hecho: reformas políticas y sistema de partidos en Colombia 2002-2010. Transformaciones en el sistema de partidos en Colombia a partir de las reformas políticas de 2003 y 2009 y la reelección presidencial. Bogotá, Institución Universitaria Politécnico Grancolombiano, 2012.

Correa Olarte María Eugenia y Cañón Murillo Nicolás, Análisis comparativo de las elecciones presidenciales y de Congreso de 2002 y 2006 y de los partidos políticos en relación con el impacto de la reforma política de 2003. Bogotá, Colombia: Universidad Gran Colombia, Ediciones Grancolombianas, 2008.

Dargent, Eduardo and Paula Muñoz, "Democracy against Parties? Party System DeInstitutionalization in Colombia." Journal of Politics in Latin America, 2011, 3:2, 43-71.

Gechem Sarmiento Carlos Eduardo, El congreso colombiano a partir de 1991, Bogotá, Colombia, Universidad Externado de Colombia, Instituto de Estudios Constitucionales Carlos Restrepo Piedrahíta, Temas de Derecho Público, No 73, 2005.

Hoskin Gary y García Sánchez Miguel, La reforma política de 2003 ¿La salvación de los partidos políticos colombianos? Bogotá: Universidad de Los Andes, Departamento de Ciencia Política, Fundación Konrad Adenauer, London School of Economics and Political Science, 2006.

Steven Levitsky, James Loxton, Brandon Van Dyck y Jorge I. Domínguez, Challenges of PartyBuilding in Latin America, Cambridge, Cambridge University Press, 2016.

Rodríguez Garavito César A., "La nueva izquierda colombiana: orígenes, características y perspectivas". En: Rodríguez Garavito César A. Barrett Patrick S., Chávez Daniel (Eds.), La nueva izquierda en América Latina. Sus orígenes y trayectoria futura. Bogotá, Grupo Editorial Norma, 2005.

Jaramillo Juan y Franco-Cuervo Beatriz, "Colombia" en: Nohlen Dieter (ed.), Elections in the Americas. A data Handbook. Vol. II South America, Oxford University Press, 2005.

Nohlen Dieter (ed.), Elections in the Americas, A data Handbook Vol. II South America, Oxford, Oxford University Press, 2005.

Rodríguez-Raga Juan Carlos, "Izquierdas y derechas en Colombia. Una mirada rápida a los rasgos sociodemográficos del espectro ideológico del país", Revista Colombia Internacional, No 66, juliodiciembre de 2007, 184-193. 
Kathleen Thelen, "Historical Institutionalism in Comparative Politics", Annu. Rev. Polit. Sci., (2), 1999, 369.

\section{Periódicos}

Periódico eltiempo.com 15/04/2015 "Yidispolítica, el escándalo que nos dejo la reelección de Uribe. La Corte condenó este miércoles a Sabas Pretelt y Diego Palacio por entregar dádivas" en <http://www.eltiempo.com/politica/justicia/que-es-la-yidispolitica/15575795> consultado 01/02/2016.

\section{Eventos}

Discursos de Gustavo Petro (líder del Movimiento Progresistas) y Marcelo Torres (líder del Partido de los Trabajadores de Colombia, PTC) en Acto político de agradecimiento al ex concejal Yezid García líder del Partido de los Trabajadores de Colombia, PTC, que hace parte de la coalición del Partido Verde, llevado a cabo el viernes 22 de enero de 2016 en Bogotá.

\section{Páginas Web}

Departamento Nacional de Estadística, DANE, Encuesta Cultura Política 2015 en <https://formularios.dane.gov.co/Anda_4_1/index.php/catalog/406> consultado 10 de abril de 2017.

Manuel Alcántara Sáenz y Flavia Freidenberg, 2001, 27 "Los partidos políticos en América Latina" en 〈http://americo.usal.es/oir/opal/pdfs/Manuel alcantara/ALHvol27alcantarafreidenberg.pdf> consultado 01/08/2017.

Ley de Partidos No 1475 en <http://www.cne.gov.co/CNE/media/file/Ley\%201475\%20de\%202011.pdf > consultado el 1 de agosto de 2017.

Observatorio Electoral 〈http://www.observatorioelectoral.org/biblioteca/?bookID=15\&page=10 $>$ consultado agosto 2015 .

Registraduría del Estado Civil en <http://elecciones.registraduria.gov.co:81/esc elec 2015/99AL/DAL16ZZZZZZZZZZZZZZZ L1.

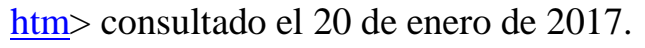

Registraduría del Estado Civil en $<$ http://www.registraduria.gov.co/Nuevas-reglas-en-lainscripcion.html> consultado 02/02/2016.

Revista virtual semana.com de 01/08/2017 "Reforma política: los puntos de honor de los partidos minoritarios. El Polo, Alianza Verde, MIRA y Opción Ciudadana se unen contra las listas cerradas y la desaparición de la pérdida de investidura. Piden bajar el umbral y hacer coaliciones en el Congreso" en <http://www.semana.com/nacion/articulo/propuestas-de-los-partidos-pequenos-a-lareforma-politica/534606> consultado 02/08/2017. 


\section{Entrevistas}

Entrevista con Camilo Vargas, internacionalista, politólogo, máster en sociología política, analista de la Misión de Observación Electoral, MOE, 15/12/2015.

Entrevista con Jorge Charry, directivo del Partido de los Trabajadores de Colombia, PTC, vocero del movimiento Progresistas, Alianza Verde 14 y15/01/2016.

Entrevista con Jorge Robledo, miembro del Comité Ejecutivo del PDA y senador por el PDA, 14 /04/2016 (Congreso de la República). 